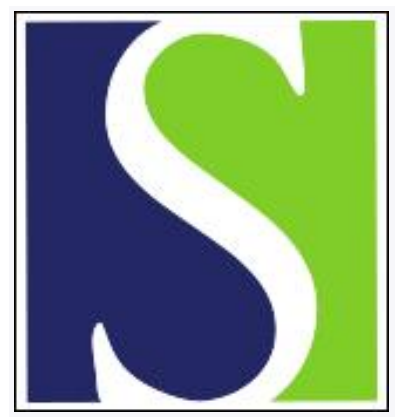

Scand J Work Environ Health 2013;39(2):125-133

https://doi.org/10.5271/sjweh.3319

Published online: 03 Sep 2012, Issue date: 01 Mar 2013

Poor health, unhealthy behaviors, and unfavorable work characteristics influence pathways of exit from paid employment among older workers in Europe: a four year follow-up study

by Robroek SJW, Schuring M, Croezen S, Stattin M, Burdorf A

The relative importance of poor health, physical inactivity, and lack of job control differed by pathway of labor force exit. Primary preventive interventions focusing on promoting physical activity and increasing job control may contribute to reducing exit from paid employment. To maintain a productive workforce, it should be considered to integrate health promotion with activities aimed at occupational health.

Affiliation: Erasmus MC, Department of Public Health, PO Box 2040, 3000 CA Rotterdam, The Netherlands. s.robroek@erasmusmc.nl

Refers to the following texts of the Journal: 2012;38(6):516-526 2011;37(6):451-453 2011;37(6):473-480 2004;30(4):287-292 $1999 ; 25(1): 42-49$

The following articles refer to this text: 2013;39(5):477-485; 2013;39(3):233-240; 2013;39(5):468-476; 2014;40(2):186-194; 2014;40(3):266-277; 2015;41(4):325-327; 2017;43(1):24-33; 2021;47(2):127-135; 2021;47(1):5-14; 2021;47(8):561-564; $2022 ; 48(7): 569-578$

Key terms: disability pension; early retirement; Europe; exit from paid employment; health; job control; longitudinal; obesity; older worker; pathway of exit; physical activity; physical work; poor health; self-perceived health; unemployment; unfavorable work characteristic; unhealthy behavior; work characteristic

This article in PubMed: www.ncbi.nlm.nih.gov/pubmed/22949091

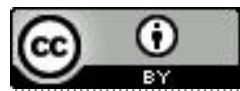




\title{
Poor health, unhealthy behaviors, and unfavorable work characteristics influence pathways of exit from paid employment among older workers in Europe: a four year follow-up study

\author{
by Suzan JW Robroek, PhD, ${ }^{1}$ Merel Schuring, PhD, ${ }^{1}$ Simone Croezen, PhD, ${ }^{1}$ Mikael Stattin, PhD, ${ }^{2}$ \\ Alex Burdorf, $P h D^{1}$
}

\begin{abstract}
Robroek SJW, Schuring M, Croezen S, Stattin M, Burdorf A. Poor health, unhealthy behaviors, and unfavorable work characteristics influence pathways of exit from paid employment among older workers in Europe: a four year follow-up study. Scand J Work Environ Health. 2013;39(2):125-133. doi:10.5271/sjweh.3319
\end{abstract}

\begin{abstract}
Objectives The aim of this study was to get insight into the role of poor health, unhealthy behaviors, and unfavorable work characteristics on exit from paid employment due to disability pension, unemployment, and early retirement among older workers.

Methods Respondents of the longitudinal Survey of Health, Ageing, and Retirement in Europe (SHARE) in 11 European countries were selected when (i) aged between 50 years and the country-specific retirement age, (ii) in paid employment at baseline, and (iii) having information on employment status during the 4-year follow-up period ( $\mathrm{N}=4923$ ). Self-perceived health, health behaviors, and physical and psychosocial work characteristics were measured by interview at baseline. Employment status was derived from follow-up interviews after two and four years. Cox proportional hazards regression analyses were used to identify determinants of unemployment, disability pension, and early retirement.

Results Poor health was a risk factor for disability pension [hazard ratio (HR) 3.90, 95\% confidence interval (95\% CI) 2.51-6.05], and a lack of physical activity was a risk factor for disability pension (HR 3.05, 95\% CI 1.68-5.55) and unemployment (HR 1.84, 95\% CI 1.13-3.01). A lack of job control was a risk factor for disability pension, unemployment, and early retirement (HR 1.30-1.77).

Conclusions Poor health, a lack of physical activity, and a lack of job control played a role in exit from paid employment, but their relative importance differed by pathway of labor force exit. Primary preventive interventions focusing on promoting physical activity as well as increasing job control may contribute to reducing premature exit from paid employment.
\end{abstract}

Key terms disability pension; early retirement; job control; longitudinal; obesity; physical activity; physical work; self-perceived health; unemployment.

Premature exit from paid employment is a serious concern at both the individual and societal level. On the individual level, exit from paid employment might not only increase the risk of financial and social problems, it might also increase the likelihood of experiencing health problems (1). On the societal level, there is a need to increase work participation and sustain a productive workforce because of decreasing birth rates and increased life expectancy in most industrialized countries (2). Therefore, many countries are developing policies to stimulate labor force participation, particularly to encourage older workers to remain at work longer. In order to develop successful interventions to reduce exit from the labor force, insight into the main determinants of exit from paid employment is needed.

From previous research it is known that poor health plays a role in exit from paid employment, particularly due to disability pension (3-6). Several studies also reported that workers with a poor health are more likely to become unemployed $(4,7-11)$ and, to a smaller extent, to retire before the statutory retirement age (4, $11,12)$.

1 Department of Public Health, Erasmus MC, Rotterdam, the Netherlands.

2 Department of Sociology, Umeå University, Umeå, Sweden.

Correspondence to: Suzan JW Robroek, Erasmus MC, Department of Public Health, PO Box 2040, 3000 CA Rotterdam, The Netherlands. [E-mail: s.robroek@erasmusmc.nl] 
Unhealthy lifestyle behaviors as well as physical and psychosocial work demands might also play a role in exit from paid employment (10). However, the evidence concerning these factors is less consistent. In a cross-sectional analysis, an unhealthy lifestyle was associated with unemployment and early retirement (13). In longitudinal studies, a slightly increased risk of early retirement was found among obese workers and workers with high physical and psychosocial work demands $(4,9,14)$. Smoking and obesity have been found to be a determinant of disability pension $(6,15-18)$. Work-related characteristics underlying Karasek's job demand-control model (19) and Siegrist's effort-reward imbalance model (20) seem to predict exit from paid employment (4).

Determinants of exit from paid employment might differ between the main pathways of leaving the labor force, particularly between the involuntary (ie, disability pension, unemployment) and more voluntary routes (ie, early retirement) of exit from work. In the current study, we aim to get insight into the role of health, health behaviors, and work characteristics on exit from paid employment due to disability pension, unemployment, and early retirement. Hereby, determinants of different routes of exit from work can be studied simultaneously. The hypothesis is that different factors play a role in different routes of exit from work. We hypothesize that poor health and unhealthy behaviors (particularly obesity and smoking) and unfavorable work characteristics (particularly low job control) will increase the likelihood of ending paid employment due to involuntary routes of exit from work.

\section{Methods}

\section{Study design and study population}

Determinants of exit from paid employment were investigated in a longitudinal study with a 4-year follow-up. The study population consisted of participants of the Survey of Health, Ageing, and Retirement in Europe (SHARE). SHARE is a longitudinal study that aims to collect health, social, and economic data on the population aged $\geq 50$ years; it started in 2004 and 2005 in 11 European Union countries (Sweden, Denmark, the Netherlands, Belgium, Germany, Austria, Switzerland, France, Italy, Spain, and Greece) (21). In the participating SHARE countries, the institutional conditions with respect to sampling were so different that a uniform sampling design for the entire project was not feasible. Different registries at the national or local level were used, enabling stratification by age. The sampling designs varied from simple random selection of households to complicated multistage designs.
Information from three waves of data collection was used for the analyses. The first wave was collected by interviews in 2004 and 2005. The overall household response across the 11 SHARE countries was $62 \%$, although substantial differences among countries were observed (21). The available dataset from the first wave of data collection (SHARE release 2.4.1) contains 28517 respondents, with 13429 (47\%) respondents aged between 50 years and the country specific-retirement age. For 118 individuals, employment status was unknown, resulting in a study population of 13311 individuals, of which 7233 (54\%) had paid employment at baseline. Of these 7233 respondents, 1748 (24\%) did not participate in the second (2006/2007) or third waves (2008/2009), and an additional 456 individuals were excluded because of conflicting $(\mathrm{N}=220)$ or missing $(\mathrm{N}=236)$ information on work status, resulting in 5029 employees or self-employed respondents aged $\geq 50$ years with baseline and follow-up information on work status. For 106 respondents $(2 \%)$, information on potential determinants of exit from work was missing. Finally, 4923 employed respondents aged $\geq 50$ were included in the analyses.

\section{Labor force participation}

The primary outcome measure in this study is selfreported work status. In the second wave of data collection, a single question asked: "In general, which of the following best describes your current employment situation? Retired, employed or self-employed, unemployed and looking for work, permanently sick or disabled, homemaker, other". Furthermore, the month and year of exit were asked. In the third wave, a life-course approach was used and all periods of paid employment and exit from paid employment were assessed by the question: "Which of these best describes your situation after you left your last job?". In case of exit from paid employment, the year of exit was asked.

Paid employment includes all individuals who (i) worked until they reached the statutory retirement age or (ii) were still at work at the end of the follow-up period. The disability pension category includes individuals stating they are permanently sick or disabled. The unemployed category includes those individuals who became unemployed from their last job before they reached the statutory retirement age. Early retirement is defined as self-reported retirement before the statutory countryspecific retirement age. An overview of country-specific retirement ages at baseline is presented in table 1. The category "other" includes persons who stopped working during follow-up due to reasons other than disability pension, unemployment, or retirement. The analysis is restricted to the first route of exit from paid employment and does not take into account re-entering paid 
Table 1. Labor force participation in participating countries. [F=female; $M=$ male; SHARE=Survey of Health, Ageing, and Retirement in Europe.]

\begin{tabular}{|c|c|c|c|c|c|c|c|c|c|}
\hline \multirow[t]{3}{*}{ Country } & \multirow[t]{3}{*}{$\mathrm{N}$} & \multicolumn{3}{|c|}{$\begin{array}{l}\text { Paid employment } \\
\text { at baseline }\end{array}$} & \multicolumn{2}{|c|}{$\begin{array}{l}\text { Retirement } \\
\text { at follow-up }\end{array}$} & \multirow{3}{*}{$\begin{array}{c}\begin{array}{c}\text { Unemployment } \\
\text { at follow-up }\end{array} \\
\% \text { in SHARE }\end{array}$} & \multirow{3}{*}{$\begin{array}{l}\text { Disability pension } \\
\text { at follow-up } \\
\% \text { in SHARE }\end{array}$} & \multirow{3}{*}{$\begin{array}{c}\begin{array}{c}\text { Other exit a } \\
\text { follow-up }\end{array} \\
\% \text { in SHARE }\end{array}$} \\
\hline & & \multirow{2}{*}{$\begin{array}{c}\begin{array}{c}\% \text { in } 0 \mathrm{ECD}{ }^{\text {a }} \\
\geq 55 \text { years }\end{array} \\
\text { Total }\end{array}$} & \multicolumn{2}{|c|}{$\begin{array}{c}\% \text { in SHARE b } \\
\geq 50 \text { years }\end{array}$} & \multirow[t]{2}{*}{$\begin{array}{l}\text { Retirement } \\
\text { age }^{c}\end{array}$} & \multirow[t]{2}{*}{$\%$ in SHARE } & & & \\
\hline & & & $\mathrm{M}$ & $\mathrm{F}$ & & & & & \\
\hline Sweden & 828 & 70.1 & 76.3 & 71.6 & 65 & 7.6 & 3.3 & 2.8 & 1.9 \\
\hline Denmark & 432 & 57.5 & 68.6 & 59.0 & 65 & 13.0 & 6.9 & 2.3 & 3.2 \\
\hline Netherlands & 520 & 53.3 & 61.7 & 38.8 & 65 & 12.7 & 3.8 & 1.9 & 6.5 \\
\hline Belgium & 654 & 35.3 & 52.9 & 35.9 & 65 & 15.4 & 3.2 & 3.1 & 5.4 \\
\hline Germany & 430 & 56.1 & 59.8 & 48.2 & 65 & 11.9 & 9.1 & 2.3 & 3.3 \\
\hline Austria & 207 & 41.1 & 44.6 & 42.0 & $60(\mathrm{~F}) / 65(\mathrm{M})$ & 24.6 & 4.8 & 4.8 & 1.4 \\
\hline Switzerland & 229 & 68.3 & 78.7 & 62.1 & $64(\mathrm{~F}) / 65(\mathrm{M})$ & 9.7 & 4.8 & 0.9 & 2.6 \\
\hline France & 541 & 38.8 & 71.6 & 62.8 & 60 & 10.0 & 3.7 & 2.3 & 1.9 \\
\hline Italy & 272 & 35.7 & 45.7 & 33.3 & $60(\mathrm{~F}) / 65(\mathrm{M})$ & 16.2 & 8.5 & 0.7 & 6.3 \\
\hline Spain & 267 & 44.1 & 60.5 & 28.9 & 65 & 7.9 & 6.4 & 1.5 & 5.6 \\
\hline Greece & 566 & 42.2 & 71.3 & 35.5 & $60(\mathrm{~F}) / 65(\mathrm{M})$ & 11.0 & 0.2 & 0.0 & 3.2 \\
\hline
\end{tabular}

a OECD data in 2009, \% workers in population 55-64 years old (40).

b SHARE data at baseline (2004-2005).

c The statutory retirement age differs per country.

employment. Most workers who exited work remained out of the labor force since it has been shown that about $20 \%$ of those who became unemployed returned to paid employment during the follow-up, and corresponding figures for disability pension and early retirement were close to zero (22). In case of multiple events, only the first event was considered. When multiple events took place at the same point in time, the following hierarchy was used: (i) disability pension, (ii) unemployment, (iii) other events, or (iv) early retirement.

\section{Health and health behaviors}

Self-perceived health was measured, using a 5-point scale, asking "Would you say your health is..." Answers ranged from "excellent" to "very poor". Poor health was defined as "less than good". Body mass index (BMI) was calculated by dividing body weight in kilogram by the square of body height in meters. BMI was categorized into normal weight $\left(<25 \mathrm{~kg} / \mathrm{m}^{2}\right)$, overweight $\left(\geq 25-<30 \mathrm{~kg} / \mathrm{m}^{2}\right)$, and obese $\left(\geq 30 \mathrm{~kg} / \mathrm{m}^{2}\right)$ (21). Physical activity was measured with separate questions on regular participation in moderate and vigorous intensity activities by asking "How often do you engage in activities that require a low or moderate level of energy such as gardening, cleaning the car, or doing a walk?" and "How often do you engage in vigorous physical activity, such as sports, heavy housework, or a job that involves physical labor?". Answers were rated on a 4-point scale ranging from "more than once a week" to "hardly ever, or never". Those who reported moderate or vigorous physical activity less than once a week were considered to have a lack of physical activity. Smoking status was measured with a single question and categorized into three categories (non-smoking, ex-smoker, and current smoker) (21). Excessive alcohol use was defined by an alcohol consumption of $>2$ glasses of alcohol beverages $\geq 5$ days a week in the past 6 months by asking "During the last 6 months, how often have you had $>2$ alcohol drinks in a single day?" (21).

\section{Work-related characteristics}

Physical work demands were measured using a single question: "My job is physically demanding. Would you say you strongly agree, agree, disagree or strongly disagree?" (23). Those individuals who (strongly) agree were considered to have a physically demanding job. Psychosocial work-related characteristics were assessed by a short battery of items derived from the Job Content Questionnaire on the demand-control model (24) and the effort-reward imbalance model questionnaire (23). All items were measured on a 4-point scale ranging from $1=$ strongly agree to $4=$ strongly disagree. Time pressure was measured using a single item: "I am under constant time pressure due to a heavy workload. Would you say you strongly agree, agree, disagree or strongly disagree?" (23). Those individuals who (strongly) agree were considered to have a high time pressure. Job control was measured by using the sum score of two items: (i) "I have very little freedom to decide how I do my work" and (ii) "I have an opportunity to develop new skills" (24). Country-specific median values were used to define a lack of job control. Rewards were measured by using the sum score of five items addressing support, recognition, salary/earnings, job promotion prospects, and job security (23). Country-specific median values were used to define a lack of rewards. The job demand- 
control model was defined as the combination of the efforts and control items, using the country-specific median values distinguishing four groups: high control and low demands, high control and high demands, low control and low demands, and high control and low demands. Effort-reward imbalance was defined as the country-specific upper tertile of the ratio of the sum score of the effort items and the sum of the reward items, both adjusted for the number of items.

\section{Demographics}

In the interview, sex, birth month and year, educational level, and marital status were asked. The highest level of education was coded according to the 1997 International Standard Classification of Education (ISCED-97) and categorized into low (pre-primary, primary, and lower secondary), intermediate (upper secondary) and high (post secondary) education. Marital status was used to categorize individuals into those who were living with a spouse or partner in the same household (cohabitation) and those living alone.

\section{Statistical analysis}

In order to calculate rates of exit from paid employment, the number of events were expressed by person-years at risk in the study population and presented as events per 1000 person-years. Descriptive statistics were used to present country-specific information on labor force participation and general characteristics of the study population.

The effect of poor health, unhealthy behaviors, and unfavorable work characteristics on labor force exit due to unemployment, disability pension, and early retirement was analyzed with Cox proportional hazards regression analyses. For each pathway out of paid employment, the event was compared with the population who stayed at work until the end of follow-up or until they reached the statutory retirement age. An individual was censored at the moment the countryspecific statutory retirement age was reached, when the individual was lost to follow-up, or at the end of the follow-up period. A random intercept was used to allow the baseline hazard function to differ between countries (25). The proportional hazards assumption was evaluated using time-dependent variables. None of the variables included in the analyses violated the proportional hazards assumption.

First, univariate relations were explored after adjustment for sex, age, educational level, and cohabitation status. All variables that were statistically significantly $(\mathrm{P}<0.05)$ related with a pathway of exit from paid employment were investigated in multivariate analyses. In order to increase the comparability between the models for the different pathways of exit from paid employment, any variable with a statistically significant relation with one pathway in the univariate analyses was also included in the multivariate model for the other pathways. A hazard ratio (HR) greater than one indicated an increased likelihood of labor force exit. The statistical analyses were carried out with IBM SPSS Statistics version 20 (SPSS Inc, Chicago, IL, USA).

\section{Results}

The study population consisted of 4923 employees with a follow-up time of 16550 person-years. In total, 22\% of the workers exited the workforce (66.0 per 1000 person-years). Most of the workers left paid employment because of early retirement $(12 \%, 35.6$ per 1000 person-years), followed by unemployment (4\%, 13.2 per 1000 person-years). A less frequent pathway of exit from paid employment was due to disability pension $(2 \%$, 6.2 per 1000 person-years). Four percent left the labor force through other pathways (11.0 per 1000 personyears), in most cases due to becoming a homemaker. Table 1 shows considerable differences in labor force participation and pathways of exit between the participating countries. The proportion of workers in paid employment corresponded strongly with the reported national figures on labor force participation (Pearson's $\mathrm{r}=0.73, \mathrm{P}=0.01$ ). On the country level, the proportion of exit due to disability pension correlated positively, although non-significantly, with the proportion of exit due to early retirement (Pearson's $r=0.57, P=0.07$ ). Nonsignificant and weak correlations were found between the other pathways of exit and labor force participation (Pearson's $\mathrm{r}<0.30$ ).

Table 2 shows the characteristics of the study population. The mean age of the study population was 55.2 years [standard deviation (SD) 3.5 years], with more male than female respondents. Older individuals and participants with a low educational level were more likely to exit from work due to disability pension, unemployment, and early retirement. Eleven percent of the participants had a less-than-good self-perceived health, and the mean BMI was $26.1 \mathrm{~kg} / \mathrm{m}^{2}$ (SD $4.1 \mathrm{~kg} / \mathrm{m}^{2}$ ). Poor health, a lack of physical activity, obesity, and all work characteristics were modestly interrelated (Pearson's $r<0.20$ ).

Individuals with a poor health, obesity, and a lack of physical activity had a higher risk of exit from paid employment through disability pension, and, almost statistically significantly, through unemployment after adjustment for sex, age, educational level, and cohabitation status (table 3 ). No statistically significant relations were found between these factors and early retirement. Excessive alcohol intake was related with early retire- 
Table 2. Individual, health, and work characteristics among $\mathrm{N}=4923$ employed individuals in Europe at baseline.

\begin{tabular}{|c|c|c|}
\hline Characteristics & $\mathrm{N}$ & $\%$ \\
\hline \multicolumn{3}{|l|}{ Demographics } \\
\hline Female gender & 2141 & 44 \\
\hline \multicolumn{3}{|l|}{ Age (years) } \\
\hline $50-54$ & 2321 & 47 \\
\hline $55-59$ & 1953 & 40 \\
\hline $60-64$ & 649 & 13 \\
\hline \multicolumn{3}{|l|}{ Educational level } \\
\hline High & 1800 & 37 \\
\hline Moderate & 1613 & 33 \\
\hline Low & 1510 & 31 \\
\hline Unmarried/not cohabitating & 929 & 19 \\
\hline \multicolumn{3}{|l|}{ Health } \\
\hline Less-than-good self-perceived & 531 & 11 \\
\hline \multicolumn{3}{|l|}{ Health behaviors } \\
\hline \multicolumn{3}{|l|}{ Body mass index } \\
\hline Normal & 2118 & 43 \\
\hline Overweight & 2083 & 42 \\
\hline Obese & 722 & 15 \\
\hline Lack of physical activity & 274 & 6 \\
\hline \multicolumn{3}{|l|}{ Smoking } \\
\hline Non-smoking & 2062 & 42 \\
\hline Former & 1530 & 31 \\
\hline Current & 1331 & 27 \\
\hline Excessive alcohol intake & 725 & 15 \\
\hline \multicolumn{3}{|l|}{ Work-related factors } \\
\hline Physically demanding job & 2270 & 46 \\
\hline High time pressure & 2762 & 56 \\
\hline Low job control & 2758 & 56 \\
\hline Low rewards & 2101 & 43 \\
\hline
\end{tabular}

ment. Of all studied work characteristics a lack of job control showed the highest increased risk for all three pathways of exit (HR 1.31-2.03), followed by low rewards (HR 1.10-1.76). Having physical job demands was not found to be related with exit from work after adjustment for demographics. Those workers with a low job control in combination with high demands (data not shown) were more likely to exit from paid employment (job demand-control: disability pension: HR 2.88, 95\% CI 1.50-5.50; unemployment: HR 1.32, 95\% CI 0.891.96 , early retirement HR $1.25,95 \%$ CI $0.99-1.58$ ), but the strength of the relation was comparable with the influence of low job control only. A combination of high efforts with low rewards did not lead to higher HR than the single effects of low rewards on exit from paid employment (effort-reward imbalance: disability pension: HR 1.53, 95\% CI 1.03-2.26; unemployment: HR $1.49,95 \%$ CI 1.14-1.95, early retirement HR 0.99 , 95\% CI 0.83-1.18).

The univariate analysis shows that poor health is an important determinant of exit through disability pension (HR 4.80, 95\% CI 3.14-7.34), but adjustment for lifestyle (HR 4.33, 95\% CI 2.80-6.69) and work (HR $3.90,95 \%$ CI 2.51-6.05) factors attenuated the strength of the relation (table 4). The relation between a lack of physical activity with disability pension and unemployment remained statistically significant, whereas the increased risk of obesity on these pathways decreased substantially after adjustment for demographics and self-perceived health. A lack of job control showed the highest increased risk for all three pathways of exit (HR 1.30-1.77), and a lack of rewards was related with unemployment (HR 1.63, 95\% CI 1.24-2.15). These associations between psychosocial factors and exit from paid employment were attenuated after adjustment for demographics and self-reported health.

\section{Discussion}

Poor health, unhealthy behaviors, and unfavorable work characteristics played a role in exit from paid employment, but their relative importance differed by pathway of labor force exit. Poor health increased the risk of disability pension, but was not related to early retirement. A lack of physical activity was a determinant of disability pension and unemployment. A lack of job control increased the likelihood of exit from paid employment through disability pension, unemployment, and early retirement.

This study investigated the effects of poor health on different pathways of exit from paid employment. It was hypothesized that poor health is an important risk factor for exit by the involuntary routes of disability pension and unemployment. In the univariate analyses, poor health was related to disability pension and with borderline significance to unemployment, and not to early retirement, which can be seen as a more voluntary pathway of exit from paid employment. The relation between poor health and disability pension is in agreement with other studies $(4,26-29)$ and is not surprising since health problems are a requirement for disability pension. Several studies have reported a significant effect of poor health on unemployment $(10,11,14,30)$, similar to the strength of the relation we found in the analysis after adjustment for demographic characteristics. Demographics attenuated the relation between poor health and unemployment from 1.56 to 1.42 . Health behaviors and psychosocial work characteristics further attenuated the relation between poor health and unemployment. Poor health might particularly be a determinant of long-term unemployment, while many other factors might play a role in shorter periods of unemployment. In the current study, we did not distinguish between unemployment durations, which might explain the difference with studies using another definition. Previous research showed large differences between countries concerning the role of poor health on unemployment, which could partly be explained by national unemployment levels (11). In the 
Table 3. Cox proportional hazard analyses on the influence of health, health behaviors, and work characteristics among employed persons on the likelihood of exit from paid employment during a follow-up period of 4 years after adjustment for demographics. All analyses adjusted for sex, age, educational level, and cohabitation status. [BMI=body mass index; HR=hazard ratio; $95 \% \mathrm{Cl}=95 \%$ confidence interval]

\begin{tabular}{|c|c|c|c|c|c|c|c|c|c|c|}
\hline & \multicolumn{2}{|c|}{$\begin{array}{c}\text { Disability pension } \\
\quad N=103 / 3441\end{array}$} & \multicolumn{2}{|c|}{$\begin{array}{c}\text { Unemployment } \\
\mathrm{N}=218 / 3983\end{array}$} & \multicolumn{2}{|c|}{$\begin{array}{c}\text { Early retirement } \\
N=589 / 4417\end{array}$} & \multicolumn{2}{|c|}{$\begin{array}{c}\text { Other } \\
\mathrm{N}=182 / 4003\end{array}$} & \multicolumn{2}{|c|}{$\begin{array}{c}\text { Total } \\
\mathrm{N}=1132 / 4923\end{array}$} \\
\hline & $\mathrm{HR}$ & $95 \% \mathrm{Cl}$ & $\mathrm{HR}$ & $95 \% \mathrm{Cl}$ & $\mathrm{HR}$ & $95 \% \mathrm{Cl}$ & $\mathrm{HR}$ & $95 \% \mathrm{Cl}$ & $\mathrm{HR}$ & $95 \% \mathrm{Cl}$ \\
\hline \multicolumn{11}{|l|}{ Health } \\
\hline Less-than-good health & $4.80^{a}$ & $3.14-7.34$ & 1.42 & $0.99-2.04$ & 1.17 & $0.91-1.51$ & 0.92 & $0.56-1.51$ & 1.10 & $0.97-1.25$ \\
\hline \multicolumn{11}{|l|}{ Health behavior } \\
\hline Normal & 1.00 & & 1.00 & & 1.00 & & 1.00 & & 1.00 & \\
\hline Overweight & 0.79 & $0.50-1.25$ & 1.10 & $0.89-1.49$ & 1.09 & $0.91-1.31$ & 0.90 & $0.65-1.25$ & 1.04 & $0.91-1.19$ \\
\hline Obese & $1.67^{\mathrm{a}}$ & $1.01-2.74$ & 1.44 & $0.99-2.08$ & 1.02 & $0.79-1.32$ & 0.87 & $0.54-1.39$ & 1.14 & $0.95-1.36$ \\
\hline Lack of physical activity & $3.58^{\mathrm{a}}$ & $2.00-6.41$ & 1.89 a & $1.16-3.06$ & 0.93 & $0.64-1.33$ & 0.74 & $0.36-1.53$ & 1.20 & $0.94-1.53$ \\
\hline \multicolumn{11}{|l|}{ Smoking } \\
\hline Non-smoking & 1.00 & & 1.00 & & 1.00 & & 1.00 & & 1.00 & \\
\hline Former & 1.14 & $0.70-1.85$ & 0.84 & $0.60-1.17$ & 0.95 & $0.78-1.15$ & 1.01 & $0.71-1.45$ & 0.96 & $0.83-1.11$ \\
\hline Current & 1.60 & $0.99-2.59$ & 1.08 & $0.78-1.49$ & 0.93 & $0.75-1.14$ & 1.15 & $0.79-1.66$ & 1.03 & $0.89-1.20$ \\
\hline Excessive alcohol intake & 1.51 & $0.89-2.57$ & 1.09 & $0.73-1.61$ & $1.29^{a}$ & $1.04-1.60$ & 1.20 & $0.80-1.79$ & $1.19^{\mathrm{a}}$ & $1.02-1.40$ \\
\hline \multicolumn{11}{|l|}{ Work-related factors } \\
\hline Physically demanding job & 1.39 & $0.94-2.08$ & 0.86 & $0.65-1.13$ & 1.08 & $0.91-1.28$ & 1.03 & $0.76-1.40$ & 1.05 & $0.93-1.18$ \\
\hline High time pressure & 1.14 & $0.77-1.70$ & 0.82 & $0.63-1.08$ & 1.00 & $0.85-1.18$ & 0.96 & $0.71-1.29$ & 0.97 & $0.86-1.10$ \\
\hline Low job control & $2.03 \mathrm{a}$ & $1.27-3.25$ & $1.61^{\mathrm{a}}$ & $1.19-2.19$ & $1.31 \mathrm{a}$ & $1.10-1.57$ & 1.04 & $0.76-1.43$ & $1.31 \mathrm{a}$ & $1.15-1.50$ \\
\hline Low rewards & $1.76^{\mathrm{a}}$ & $1.19-2.60$ & $1.74^{\mathrm{a}}$ & $1.33-2.28$ & 1.10 & $0.94-1.30$ & $1.41^{\mathrm{a}}$ & $1.05-1.89$ & $1.27^{\mathrm{a}}$ & $1.13-1.43$ \\
\hline
\end{tabular}

a $\mathrm{P}<0.05$, adjusted for age, sex, educational level, and cohabitation status.

Table 4. Multivariate cox proportional hazard analyses on the influence of health, health behaviors, and work characteristics among employed persons on the likelihood of exit from paid employment during a follow-up period of 4 years. [BMI= body mass index; HR=hazard ratio; $95 \% \mathrm{Cl}=95 \%$ confidence interval]

\begin{tabular}{|c|c|c|c|c|c|c|c|c|c|c|}
\hline & \multicolumn{2}{|c|}{$\begin{array}{c}\text { Disability pension } \\
N=103 / 3441\end{array}$} & \multicolumn{2}{|c|}{$\begin{array}{c}\text { Unemployment } \\
\mathrm{N}=218 / 3983\end{array}$} & \multicolumn{2}{|c|}{$\begin{array}{c}\text { Early retirement } \\
\mathrm{N}=589 / 4417\end{array}$} & \multicolumn{2}{|c|}{$\begin{array}{c}\text { Other } \\
\mathrm{N}=182 / 4003\end{array}$} & \multicolumn{2}{|c|}{$\begin{array}{c}\text { Total } \\
\mathrm{N}=1092 / 4923 \\
\end{array}$} \\
\hline & $\mathrm{HR}$ & $95 \% \mathrm{Cl}$ & $\mathrm{HR}$ & $95 \% \mathrm{Cl}$ & $\mathrm{HR}$ & $95 \% \mathrm{Cl}$ & $\mathrm{HR}$ & $95 \% \mathrm{Cl}$ & $\mathrm{HR}$ & $95 \% \mathrm{Cl}$ \\
\hline \multicolumn{11}{|l|}{ Health } \\
\hline Less-than-good health & 3.90 a & $2.51-6.05$ & 1.21 & $0.84-1.76$ & 1.17 & $0.90-1.51$ & 0.88 & $0.53-1.45$ & 1.29 a & $1.08-1.53$ \\
\hline \multicolumn{11}{|l|}{$\begin{array}{l}\text { Health behavior } \\
\text { BMI }\end{array}$} \\
\hline Normal & 1.00 & & 1.00 & & 1.00 & & 1.00 & & 1.00 & \\
\hline Overweight & 0.80 & $0.51-1.28$ & 1.07 & $0.79-1.46$ & 1.08 & $0.90-1.30$ & 0.90 & $0.65-1.24$ & 1.03 & $0.90-1.17$ \\
\hline Obese & 1.29 & $0.78-2.15$ & 1.36 & $0.94-1.99$ & 1.01 & $0.79-1.31$ & 0.88 & $0.55-1.41$ & 1.10 & $0.92-1.31$ \\
\hline Lack of physical activity & $3.05^{\mathrm{a}}$ & $1.68-5.55$ & $1.84^{\mathrm{a}}$ & $1.13-3.01$ & 0.94 & $0.65-1.35$ & 0.77 & $0.37-1.58$ & 1.18 & $0.93-1.51$ \\
\hline Excessive alcohol intake & 1.55 & $0.90-2.66$ & 1.10 & $0.74-1.64$ & $1.31^{\mathrm{a}}$ & $1.06-1.63$ & 1.20 & $0.80-1.79$ & $1.21^{\mathrm{a}}$ & $1.03-1.43$ \\
\hline \multicolumn{11}{|l|}{ Work-related factors } \\
\hline Low job control & $1.77^{\mathrm{a}}$ & $1.10-2.84$ & $1.43^{\mathrm{a}}$ & $1.05-1.96$ & $1.30^{\mathrm{a}}$ & $1.08-1.57$ & 0.98 & $0.71-1.36$ & $1.26^{\mathrm{a}}$ & $1.10-1.44$ \\
\hline Low rewards & 1.44 & $0.96-2.16$ & $1.63^{a}$ & $1.24-2.15$ & 1.03 & $0.87-1.22$ & $1.42^{\mathrm{a}}$ & $1.05-1.92$ & 1.19 a & $1.06-1.35$ \\
\hline
\end{tabular}

a $\mathrm{P}<0.05$, adjusted for age, sex, educational level, cohabitation status, and the variables included in the table.

current study, no major differences were found between countries with high or low labor force participation among older individuals (data not shown).

There is considerable debate concerning the role of health in retirement and specifically early retirement. In a systematic review, poor health was found to be a risk factor for early retirement (31). Based on our results, early retirement is not driven by health problems. Other factors, like financial arrangements and social factors, might be of greater importance for voluntary routes of exit (5). The discrepancy between studies on the influence of poor health on early retirement might partly be explained by different definitions of early retirement. In the current study, early retirement was defined as retirement before the official full retirement age. In other studies early retirement also includes disability pension or unemployment $(12,32)$. No differences were found in the relation between poor health and unemployment after stratifying Bismarckian countries (Austria, Belgium, France, Germany, Netherlands, Switzerland), Scandinavian countries (Sweden, Denmark), and Southern Europe (Greece, Italy, Spain). Within countries, workers with different occupations might be handled differently. This could explain why workers in jobs with 
low job control are more likely to exit paid employment through disability pension.

The role of unhealthy behaviors in the working population has mostly been studied in relation to work ability, productivity loss at work, and sick leave, showing that lifestyle factors and a healthy body weight are of importance in keeping the workforce healthy and productive (16, 33-35). It has been shown that particularly smoking and obesity were determinants of disability pension $(6,15-18)$. In a study among employees in the construction industry, an unhealthy lifestyle predicted unemployment (10). The current study shows that the role of health behaviors differ between the pathways of leaving paid employment. A lack of physical activity was related with exit from paid employment due to disability pension and unemployment, but not due to early retirement. In the univariate analyses, obese workers also had a higher risk of exit, and after adjustment for potential confounders the estimate of obesity on exit from paid employment still indicates an increased, although non-significant, risk on disability pension and unemployment. The role of lifestyle factors on exit from work differs between countries. Overweight and obesity were more likely to be related with exit from work due to disability pension and unemployment in Bismarckian and Scandinavian countries than in Southern Europe (data not shown). Furthermore, smoking was only significantly related with exit from work in the Scandinavian region. Promoting a healthy lifestyle, particularly physical activity, might be a way to prevent workers from leaving the work force prematurely. To gain insight into the role of lifestyle on sustained labor participation, studies with a long follow-up period and repeated measurements are needed.

Another important issue is how to keep those workers with health problems at work without deteriorating their health. Favorable working conditions might play an important role in keeping workers healthy and keeping workers with health problems in paid employment. This implies that the work and working conditions need to be improved to sustain employability (36). In previous studies, a lack of job control and an imbalance between efforts and rewards were found to be associated with exit from paid employment $(32,37)$. This is in accordance with the current study. A lack of job control as well as low rewards were related to several pathways of exit from paid employment. The relation between these single underlying factors of respectively the job demand-control model and the effort-reward imbalance model with exit from paid employment was, except for disability pension, stronger than the combined factors. In contrast with the psychosocial work factors, no relation was found between physical job demands and exit from work after adjustment for demographic and health factors. This result might be biased due to the healthy worker effect, in which workers with physically demanding jobs had to exit their job or paid employment before reaching the age of 50 years.

There are some limitations in this study. The first is the household response of $62 \%$, which is comparable with other European studies (38). The proportion of workers in paid employment in the study population corresponded strongly with the reported national figures on labor force participation. However, bias due to non-response cannot be ruled out in the current study. Additionally, $30 \%$ of the included respondents at baseline were lost to follow-up. In the analyses between respondents and non-respondents at followup, no major differences were found in health, health behaviors, and work characteristics. A second limitation is the large variation between European countries in the association between poor health and exit from paid employment (13). These variations might reflect differences between countries in the definitions of the specific pathways of exit from paid employment and institutional arrangements. Since there is a lack of power to study the determinants of labor force exit per country, countries were considered as different strata in the multivariate analyses. In Greece, none of the respondents stated they exited paid employment due to disability pension. Therefore, the Greek respondents were not included in the analysis on exiting through this specific pathway. A third limitation is that all data rely on self-reports. The assessment of self-perceived health has been found to be useful in evaluating health status in large epidemiologic studies and shown to be a strong predictor of mortality (39). A fourth limitation is the combination of employees and self-employed individuals, particularly concerning the "rewards" work factor. It was not possible to distinguish the selfemployed individuals from the employees. Another limitation is potential confounding. For example, a lack of job control may be linked to other important job characteristics that are not measured in SHARE. Furthermore, in the analysis on work-related factors one must bear in mind that the self-rated psychosocial factors may reflect a large variety of particular work processes and situations that contribute differently to the observed role of these factors in exit from paid employment.

In conclusion, poor health, a lack of physical activity, and lack of job control played a role in exit from paid employment, but their relative importance differed by pathway of labor force exit. Primary preventive interventions focusing on promoting physical activity as well as increasing job control may contribute to reducing premature exit from paid employment. To maintain a productive workforce, it should be considered to integrate health promotion activities with activities aimed at occupational health and safety. 


\section{Acknowledgements}

This paper uses data from SHARELIFE release 1, as of 24 November 2010 or SHARE release 2.4.0, as of 24 May 2011. The SHARE data collection has been primarily funded by the European Commission through the $5^{\text {th }}$ framework program (project QLK6-CT-2001- 00360 in the thematic program Quality of Life), through the $6^{\text {th }}$ framework program (projects SHARE-I3, RII-CT2006-062193, COMPARE, CIT5-CT-2005-028857, and SHARELIFE, CIT4-CT-2006-028812) and through the $7^{\text {th }}$ framework program (SHARE-PREP, 211909 and SHARE-LEAP, 227822). Additional funding from the US National Institute on Aging (U01 AG09740-13S2, P01 AG005842, P01 AG08291, P30 AG12815, Y1-AG4553-01 and OGHA 04-064, IAG BSR06-11, R21 AG025169) as well as from various national sources is gratefully acknowledged (see www.share-project.org for a full list of funding institutions).

This paper is based on work funded by The Netherlands Organization for Health Research and Development (ZonMw project number: 200400001).

\section{References}

1. Gallo WT, Bradley EH, Siegel M, Kasl SV. Health effects of involuntary job loss among older workers: findings from the health and retirement survey. J Gerontol B Psychol Sci Soc Sci. 2000 May;55(3):S1314-40. http://dx.doi.org/10.1093/ geronb/55.3.S131.

2. Ilmarinen JE. Aging workers. Occup Environ Med. 2001 Aug;58(8):546-52. http://dx.doi.org/10.1136/oem.58.8.546.

3. Pedersen J, Bjorner JB, Burr H, Christensen KB. Transitions between sickness absence, work, unemployment, and disability in Denmark 2004-2008. Scand J Work Environ Health. 2012 Mar 22. [Epub ahead of print]. http://dx.doi.org/10.5271/ sjweh.3293.

4. van den Berg T, Schuring M, Avendano M, Mackenbach J, Burdorf A. The impact of ill health on exit from paid employment in Europe among older workers. Occupational and Environmental Medicine. 2010 Dec;67(12):845-52. http://dx.doi.org/10.1136/oem.2009.051730.

5. Nilsson K, Hydbom AR, Rylander L. Factors influencing the decision to extend working life or retire. Scand J Work Environ Health. 2011 Nov;37(6):473-80. http://dx.doi.org/10.5271/ sjweh.3181.

6. Lund T, Csonka A. Risk factors in health, work environment, smoking status, and organizational context for work disability. Am J Ind Med. 2003 Nov;44(5):492-501. http://dx.doi. org/10.1002/ajim.10298.

7. Bartley M. Unemployment and ill health: understanding the relationship. J Epidemiol Community Health. 1994
Aug;48(4):333-7. http://dx.doi.org/10.1136/jech.48.4.333.

8. Cai L, Kalb G. Health status and labour force participation: evidence from Australia. Health Econ. 2006 Mar;15(3):24161. http://dx.doi.org/10.1002/hec.1053.

9. Friis K, Ekholm O, Hundrup YA, Obel EB, Gronbaek M. Influence of health, lifestyle, working conditions, and sociodemography on early retirement among nurses: the Danish Nurse Cohort Study. Scand J Public Health. 2007;35(1):23-30. http://dx.doi.org/10.1080/14034940600777278.

10. Leino-Arjas P, Liira J, Mutanen P, Malmivaara A, Matikainen E. Predictors and consequences of unemployment among construction workers: prospective cohort study. BMJ. 1999 Sep 4;319(7210):600-5. http://dx.doi.org/10.1136/ bmj.319.7210.600.

11. Schuring M, Burdorf L, Kunst A, Mackenbach J. The effects of ill health on entering and maintaining paid employment: evidence in European countries. J Epidemiol Community Health. 2007 Jul;61(7):597-604. http://dx.doi.org/10.1136/ jech.2006.047456.

12. Karpansalo M, Manninen P, Kauhanen J, Lakka TA, Salonen JT. Perceived health as a predictor of early retirement. Scand J Work Environ Health. 2004 Aug;30(4):287-92. http://dx.doi. org/10.5271/sjweh.796.

13. Alavinia SM, Burdorf A. Unemployment and retirement and ill-health: a cross-sectional analysis across European countries. Int Arch Occup Environ Health. 2008 Oct;82(1):39-45. http:// dx.doi.org/10.1007/s00420-008-0304-6.

14. Jusot F, Khlat M, Rochereau T, Serme C. Job loss from poor health, smoking and obesity: a national prospective survey in France. J Epidemiol Community Health. 2008 Apr;62(4):332 7. http://dx.doi.org/10.1136/jech.2007.060772.

15. Albertsen K, Lund T, Christensen KB, Kristensen TS, Villadsen E. Predictors of disability pension over a 10-year period for men and women. Scand J Public Health. 2007;35(1):78-85. http://dx.doi.org/10.1080/14034940600858474.

16. Lund T, Labriola M, Feveile H, Christensen KB. The fraction of disability pensions attributable to smoking and obesity. Results from a 15-year follow-up study. Journal of Public Health. 2010 June;18(3):251-4. http://dx.doi.org/10.1007/ s10389-009-0304-3.

17. Neovius K, Neovius M, Rasmussen F. The combined effects of overweight and smoking in late adolescence on subsequent disability pension: a nationwide cohort study. Int $\mathrm{J}$ Obes (Lond). 2010 Jan;34(1):75-82. http://dx.doi.org/10.1038/ ijo.2009.178.

18. Ropponen A, Narusyte J, Alexanderson K, Svedberg P. Stability and change in health behaviours as predictors for disability pension: a prospective cohort study of Swedish twins. BMC Public Health. 2011;11:678. http://dx.doi. org/10.1186/1471-2458-11-678.

19. Karasek R, Baker D, Marxer F, Ahlbom A, Theorell T. Job decision latitude, job demands, and cardiovascular disease: a prospective study of Swedish men. Am J Public Health. 1981 Jul;71(7):694-705. http://dx.doi.org/10.2105/ AJPH.71.7.694. 
20. Siegrist J, Starke D, Chandola T, Godin I, Marmot M, Niedhammer I, et al. The measurement of effort-reward imbalance at work: European comparisons. Soc Sci Med. 2004 Apr;58(8):1483-99. http://dx.doi.org/10.1016/S02779536(03)00351-4.

21. Borsch-Supan A, Jurges, H, Mackenbach, J, Siegrist, J, Weber, G. Health, Ageing and Retirement in Europe. First results from the survey of Health, Ageing and Retirement in Europe. First results from thesurvey of Health, Ageing and Retirement in Europe. Mannheim; 2005.

22. Burdorf A, van den Berg TI, Avendano M, Kunst A, Mackenbach J. The effects of ill health on displacement from the labour market and potential impact of prevention. In: Börsch-Supan A, editor. Health, Ageing and Retirement in Europe (2004-2007) - Starting the longitudinal dimension. Mannheim: MEA; 2008. p. 137-42.

23. Siegrist J. Adverse health effects of high-effort/low-reward conditions. J Occup Health Psychol. 1996 Jan;1(1):27-41. http://dx.doi.org/10.1037/1076-8998.1.1.27.

24. Karasek R, Brisson C, Kawakami N, Houtman I, Bongers P, Amick B. The Job Content Questionnaire (JCQ): an instrument for internationally comparative assessments of psychosocial job characteristics. J Occup Health Psychol. 1998 Oct;3(4):322-55. http://dx.doi.org/10.1037/10768998.3.4.322.

25. Twisk J. Applied longitudinal data analyses for epidemiology. A practical guide. Cambridge, UK: Cambridge University Press; 2003.

26. Mansson NO, Rastam L. Self-rated health as a predictor of disability pension and death--a prospective study of middleaged men. Scand J Public Health. 2001 Jun;29(2):151-8. http://dx.doi.org/10.1177/14034948010290020201.

27. Biering-Sorensen F, Lund J, Hoydalsmo OJ, Darre EM, Deis A, Kryger P, et al. Risk indicators of disability pension. A 15 year follow-up study. Dan Med Bull. 1999 Jun;46(3):258-62.

28. Krokstad S, Johnsen R, Westin S. Social determinants of disability pension: a 10-year follow-up of 62000 people in a Norwegian county population. Int J Epidemiol. 2002 Dec;31(6):1183-91. http://dx.doi.org/10.1093/ije/31.6.1183.

29. Ropponen A, Silventoinen K, Svedberg P, Alexanderson K, Koskenvuo K, Huunan-Seppala A, et al. Health-related risk factors for disability pensions due to musculoskeletal diagnoses: a 30-year Finnish twin cohort study. Scand J Public Health. 2011 Dec;39(8):839-48. http://dx.doi. org/10.1177/1403494811418283.
30. Liira J, Leino-Arjas P. Predictors and consequences of unemployment in construction and forest work during a 5-year follow-up. Scand J Work Environ Health. 1999 Feb;25(1):429. http://dx.doi.org/10.5271/sjweh.382.

31. van den Berg TI, Elders LA, Burdorf A. Influence of health and work on early retirement. J Occup Environ Med. 2010 Jun;52(6):576-83. http://dx.doi.org/10.1097/ JOM.0b013e3181de8133.

32. Coe NB, Zamarro G. Retirement effects on health in Europe. J Health Econ. 2011 Jan;30(1):77-86. http://dx.doi. org/10.1016/j.jhealeco.2010.11.002.

33. Neovius K, Johansson K, Kark M, Neovius M. Obesity status and sick leave: a systematic review. Obes Rev. 2009 Jan;10(1):17-27. http://dx.doi.org/10.1111/j.1467789X.2008.00521.x.

34. Robroek SJ, van den Berg TI, Plat JF, Burdorf A. The role of obesity and lifestyle behaviours in a productive workforce. Occup Environ Med. 2011 Feb;68(2):134-9. http://dx.doi. org/10.1136/oem.2010.055962

35. van den Berg TI, Elders LA, de Zwart BC, Burdorf A. The effects of work-related and individual factors on the Work Ability Index: a systematic review. Occup Environ Med. 2009 Apr;66(4):211-20. http://dx.doi.org/10.1136/ oem.2008.039883.

36. Harma M. Adding more years to the work careers of an aging workforce--what works? Scand J Work Environ Health. 2011 Nov;37(6):451-3. http://dx.doi.org/10.5271/sjweh.3198.

37. Laine S, Gimeno D, Virtanen M, Oksanen T, Vahtera J, Elovainio M, et al. Job strain as a predictor of disability pension: the Finnish Public Sector Study. J Epidemiol Community Health. 2009 Jan;63(1):24-30. http://dx.doi. org/10.1136/jech.2007.071407.

38. Peracchi F. The European Community Household Panel: A review empirical economics. 2002;27(1):63-90.

39. Burstrom B, Fredlund P. Self rated health: Is it as good a predictor of subsequent mortality among adults in lower as well as in higher social classes? J Epidemiol Community Health. 2001 Nov;55(11):836-40. http://dx.doi.org/10.1136/ jech.55.11.836.

40. OECD. Employment to population ratios. Paris:OECD. Accessed 31 August 2012. Available from: www.oecd.org/do cument/22/0,3746,en_2649_33927_43221014_1_1_1_1,00. html\#erate.

Received for publication: 21 May 2012 